\title{
The Most Undertreated Chronic Disease: Addressing Obesity in Primary Care Settings
}

\author{
Shanna Tucker ${ }^{1} \cdot$ Carolyn Bramante $^{2,3} \cdot$ Molly Conroy $^{4} \cdot$ Angela Fitch $^{5} \cdot$ Adam Gilden $^{6,7} \cdot$ Sandra Wittleder $^{1}$. \\ Melanie Jay ${ }^{8,9}$
}

Accepted: 22 June 2021 / Published online: 23 July 2021

(C) This is a U.S. government work and not under copyright protection in the U.S.; foreign copyright protection may apply 2021

\begin{abstract}
Purpose of Review While obesity-related comorbidities are frequently addressed and treated in primary care (PC), obesity itself is undertreated. We review the current treatments for obesity and provide potential provider and system-level strategies for integrating weight management and improving longer term obesity care within PC settings.

Recent Findings We now understand that the body develops multiple mechanisms to resist weight loss and promote weight regain, making both weight loss and weight loss maintenance challenging. Therefore, weight management often requires medically supervised interventions and should be treated on a long-term basis. However, there are multiple barriers to improving obesity care within PC settings.

Summary Clinically, utilizing strategies such as a shared decision-making approach and the 5As to discuss treatment options can facilitate formulating an obesity treatment plan. Utilizing telehealth, a team-based approach, and community partnering can increase patient access to intensive behavioral interventions. Future studies should evaluate other cost-effective methods to implement obesity care into the PC setting.
\end{abstract}

Keywords Obesity $\cdot$ Weight management $\cdot$ Primary care $\cdot$ Challenges/barriers $\cdot$ Shared decision making

This article is part of the Topical Collection on Obesity Treatment

Melanie Jay

melanie.jay@nyulangone.org

1 Department of Medicine, NYU Grossman School of Medicine, New York, NY, USA

2 Division of General Internal Medicine, University of Minnesota Medical School, Minneapolis, MN, USA

3 Center for Pediatric Obesity Medicine, University of Minnesota Medical School, Minneapolis, MN, USA

4 University of Utah School of Medicine, Salt Lake City, UT, USA

5 Departments of Medicine and Surgery, Massachusetts General Hospital Weight Center, Harvard Medical School, Boston, MA, USA

6 Kaiser Permanente Colorado, Denver, CO, USA

7 University of Colorado School of Medicine, Aurora, CO, USA

8 Departments of Medicine and Population Health, NYU Grossman School of Medicine, New York, NY, USA

9 New York Harbor Veterans Affairs, New York, NY, USA

\section{Introduction}

Obesity was defined as a disease by the World Health Organization and Centers for Medicaid and Medicare in 2013 [1]. Worldwide, the prevalence of obesity has tripled since 1975 [1], and it is one of the leading causes of death in the United States (US) and worldwide [2]. Obesity is caused by complex interactions between genetic, behavioral, and environmental influences [3-5]. These influences lead to accumulation of adipose tissue and dysregulation of the body's energy regulatory systems, making weight loss difficult [5]. Obesity is associated with reduced quality of life, poorer mental health, and serious comorbid conditions including cardiovascular disease, diabetes, and cancer [6, 7].

While obesity-related comorbidities are frequently addressed in primary care (PC), obesity itself is chronically undertreated [8-11]. A cross-sectional study of National Health and Nutrition Examination Survey (NHANES) data between 2011 and 2018 showed that only $40 \%$ of adults with overweight or obesity reported that they received counseling to lose weight [12]. By under-treating obesity in PC, we miss a valuable opportunity to reach many patients and improve their 
overall health. Considering there are over 480 million PC visits per year across the US [13], successfully integrating obesity treatment into PC could have a substantial public health impact and meaningfully address the obesity epidemic. However, there are several challenges to improving the care of obesity in PC settings.

The authors of this article are a group of primary care and obesity clinicians and researchers, committed to improving obesity-related treatment in PC settings. We will review the evidence for current treatments and provide examples and recommendations to incorporate established clinical guidelines into a PC practice.

\section{Diagnosis and Classification of Obesity}

In this review, we will refer to the following terms: overweight (BMI $25.0-29.9 \mathrm{~kg} / \mathrm{m}^{2}$ ), class I obesity (BMI $30-34.9 \mathrm{~kg} / \mathrm{m}^{2}$ ), class II obesity (BMI $35-39.9 \mathrm{~kg} / \mathrm{m}^{2}$ ), and class III obesity $\left(\mathrm{BMI} \geq 40 \mathrm{~kg} / \mathrm{m}^{2}\right)$. When evaluating and treating obesity, it is important to classify obesity to help guide treatment, as higher obesity class is associated with increased mortality [14-16].

\section{A Review on Current Treatments for Obesity}

\section{Lifestyle and Behavioral Therapy}

Structured lifestyle intervention is fundamental to the treatment of obesity, even when pharmacotherapy and surgery are indicated [17]. The United States Preventive Services Task Force (USPSTF) recommends that clinicians offer or refer patients with obesity $\left(\mathrm{BMI} \geq 30 \mathrm{~kg} / \mathrm{m}^{2}\right.$ ) to intensive, multicomponent behavioral interventions as a grade $\mathrm{B}$ recommendation [18].

Behavioral interventions are meant to improve adherence to lifestyle recommendations. These can include self-monitoring, goal-setting, stimulus control (e.g., reducing the availably of tempting foods), stress reduction, improved sleep quantity and quality, and/or psychological therapy $[17,18]$.

To qualify as "intensive", the USPSTF recommends at least 12 sessions where weight management is discussed over 1 year. The intervention should last at least $1-2$ years, with a 3-12 month "core" phase where the majority of the weight loss occurs followed by a 9-12 months "maintenance" phase [18]. Evidence supports making small incremental changes with frequent and long-term follow-up to provide accountability and make adjustments to the approach when needed [17].

A "multicomponent" intervention combines behavior modification with other strategies (e.g., cognitive therapy, group sessions, dietary education) to change one's lifestyle habits [19]. One well-known example of an intensive, multicomponent intervention is the Diabetes Prevention Program (DPP), which was originally provided as one-on-one sessions and has been adapted to group sessions [20]. Healthcare system-based weight management programs or interventions such as the MOVE! Weight Management Program at the Veterans Health Administration (VHA) [21, 22] or commercial programs such as WW (Weight Watchers) have also been found to be effective [23].

\section{A Healthy Meal Plan}

Reduced caloric intake is necessary to create an energy deficit and promote weight loss [17]. The American Heart Association/American College of Cardiology/The Obesity Society (AHA/ACC/TOS) guidelines discuss three different strategies for prescribing a reduced calorie diet. These include (1) 1200-1500 kcal/day for women and 1500-1800 kcal/day for men, (2) 500-750 kcal/day energy deficit (e.g., cutting out soda and snack foods), or (3) prescribing one of the evidencebased diets that restrict certain food types to create an energy deficit (e.g., DASH, Mediterranean, or low carbohydrate diet) [24-26, 27•].

Studies show that the relationship between different macronutrients is complex and that adjusting the macronutrient components of a patient's meal plan can facilitate weight loss [26]. Food properties such as satiety value, taste, and energy density are powerful determinants of total calories ingested. For instance, high fat diets tend to have higher energy density, complex carbohydrates can facilitate reduction in energy intake, and protein has a high satiety effect [26]. We encourage clinicians to consider these properties when discussing dietary recommendations with patients. For instance, if a patient reports hunger shortly after having a meal, increasing their protein content of each meal may prolong their satiety and stave off hunger.

Meal replacements can also be incorporated into a patient's meal plan to help them adhere to a reduced calorie diet. Multiple studies have shown that incorporating meal replacements even for just one or two meals per day can lead to greater weight loss, compared to a meal plan comprised of the same calorie target using only "conventional" foods [28]. Meal replacements have several benefits that allow patients to adhere to their meal plans besides calorie control, including portion control, structured eating, stimulus narrowing and control, and palatability [11]. Meal replacements can successfully be used in the PC setting for weight loss and weight maintenance [29, 30]. Currently, there is no established definition of a "meal replacement", and food products can include beverages, snacks/bars, and prepared meals/entrees and can be purchased at a weight loss clinic, commercial weight loss center, or over the counter. Generally, we recommend that each meal replacement contain $20-30 \mathrm{~g}$ of protein, at least $5 \mathrm{~g}$ of fiber, fewer than $10 \mathrm{~g}$ of carbohydrates, fewer than $5 \mathrm{~g}$ of fat, and be supplemented with all essential vitamins and 
nutrients. A prescribed meal plan with meal replacements should last for at least 2 weeks and can be prescribed indefinitely without any laboratory monitoring if it has at least 1200 $\mathrm{kcal} /$ day [27•]. However, to most effectively incorporate meal replacements and prevent attrition, regular follow-up is needed to provide continued education, counseling, and track progress [31]. Patients with diabetes especially require intensive self-monitoring of blood glucose [31].

While patients may inquire about a specific or popular diet, there is not enough evidence to prescribe one diet over another. A reduced calorie meal plan should be selected to reflect patients' personal and cultural preferences to promote adherence. It is also important to meet patients where they are in their dietary behaviors. For one patient, it may be reasonable to recommend a high protein, low carbohydrate diet. For another patient who is eating fast food for each meal, focusing on making more meals at home and on ensuring fruits and vegetables are consumed with each meal may be a more achievable starting goal.

\section{Physical Activity}

Increasing physical activity (PA) and decreasing number of sedentary hours should be discussed at every visit, as PA is important for both initial weight loss and weight maintenance. Multiple meta-analyses have shown that doing $\geq 150 \mathrm{~min} /$ week of moderate intensity activity leads to weight loss when combined with a reduced calorie diet [32-34]. In terms of weight-loss maintenance, studies show that $200-300 \mathrm{~min} /$ week is required to attenuate weight regain [35] and increased exercise is associated with longer term weight loss [36-38]. Aerobic activity should be the major component of a PA plan, as it has been shown to have the highest potential to reduce visceral adipose tissue [39]. Resistance training should also be included to preserve lean muscle [17], which is particularly important in post-menopausal women [40]. We recommend assessing patients' current PA levels and capabilities to individualize PA plans [17]. For some patients, a reasonable first goal may be to reduce recreational screen time to reduce prolonged sitting.

\section{Pharmacotherapy}

\section{Medication Reconciliation - Reconsider Medications that Promote Weight Gain}

Before prescribing weight-loss medications, a PC provider (PCP) should use their longitudinal relationship to ensure current medications are not contributing to weight gain. Although medication reconciliation is typically done at all clinic visits, for patients with overweight or obesity, special attention should be taken to attempt to replace medications that promote weight gain with alternative medications that are weight neutral or promote weight loss, as this may attenuate weight gain.
The Obesity Action Coalition (OAC) offers a succinct list of common medications to consider replacing with a medication that is weight neutral or promotes weight loss (https://www. obesityaction.org/wp-content/uploads/prescription medications.pdf).

\section{Benefits of Pharmacotherapy}

Prescription medications used to treat overweight and obesity are currently referred to as "anti-obesity medications" to emphasize the goal of treating a disease.

In the 2018 USPSTF systematic review, pharmacotherapybased weight loss trials showed greater weight loss and decrease in waist circumference, higher likelihood of losing $5 \%$ of body weight, and better weight-loss maintenance compared with placebo groups [41]. The expected weight loss with lifestyle is 5$10 \%$, and the addition of medications increases the likelihood of attaining clinically significant weight loss [17]. While lifestylebased interventions are at the foundation of any obesity treatment plan, we often see less success when used alone, in part due to the pathophysiology of obesity [17]. Once obesity develops, metabolic adaptations and alterations in hunger and satiety signals often lead to weight regain [41]. The purpose of medications is to help patients adhere to the reduced calorie diets by combating the body's mechanisms to resist weight loss. Typically, antiobesity medications do this by controlling appetite and regulating hunger and satiety signals. As with other diseases such as diabetes and hypertension, PCPs must understand the key biological underpinning of obesity and use any tools available for treatment, including pharmacotherapy. Additionally, some anti-obesity medications, such as glucagon-like peptide 1-receptor agonists (GLP-1RAs), have beneficial effects on cardiovascular outcomes and mortality $[42,43]$.

\section{Who Should Be Started on Pharmacotherapy?}

Current indications for anti-obesity medications are BMI $\geq$ $30 \mathrm{~kg} / \mathrm{m}^{2}$ or BMI $\geq 27 \mathrm{~kg} / \mathrm{m}^{2}$ with obesity-related comorbidities [24, 44]. Pharmacotherapy should especially be considered for patients who have not met weight-loss goals ( $\geq 5 \%$ of total body weight at 3-6 months) with lifestyle intervention alone. The decision to initiate drug therapy should be individualized, weighing the risks and benefits of all treatment options. Medications should always be used as an adjunct to lifestyle modifications. A medication should be continued for no longer than 3 months if no significant weight loss is seen [45•], at which point the medication options should be reassessed.

\section{Off-Label Medications for Weight Loss}

Metformin Consider metformin for patients with pre-diabetes or diabetes with overweight or obesity who are not already on 
medical therapy. While studies have shown that metformin can lead to greater weight loss compared to placebo even in people who do not have diabetes or insulin resistance [46, 47], greater weight loss is achieved in patients that have some evidence of insulin resistance [46].

Topiramate Topiramate is FDA-approved for migraine prophylaxis and epilepsy. For weight management, topiramate has been well-studied in patients with and without type 2 diabetes. In patients with overweight/obesity and type 2 diabetes, topiramate produced significantly greater weight loss compared to placebo, improvements in hemoglobin A1c [48, 49], and body fat [49]. Similarly, in patients without type 2 diabetes, topiramate was more likely to produce clinically significant weight loss compared to placebo [50].

Topiramate has also been found to be effective in preventing weight gain associated with binge eating disorder. Binge eating disorder (BED) is treatable eating disorder that is characterized by recurrent episodes of eating large quantities or food, often associated with a feeling of a loss of control during these episodes and shame and/or distress, and without regular compensatory measures to prevent weight gain [51, 52]. Multiple studies have shown that when used to treat binge eating disorder in patients with obesity, topiramate can reduce the number of binge episodes per week and per day, weight, and BMI [53-55]. We do highly recommend considering and discussing psychotherapy for treatment of BED even in cases where pharmacotherapy is utilized [56].

Lastly, topiramate has also been shown to lead to weight loss in co-administration with antipsychotics for treatment of schizophrenia [57, 58].

GLP-1RAs The American Diabetes Association recommends adding a GLP-1RA or an SLGT-2 inhibitor for patients with type 2 diabetes as the next step in therapy for patients already on metformin with a need to lose weight or minimize weight gain if there are no contraindications [59]. Currently, only two GLP-1Ras are approved for treatment of obesity - liraglutide $3.0 \mathrm{mg}$ daily and semaglutide $2.4 \mathrm{mg}$ weekly. However, a systematic review showed that compared to placebo, all GLP1RAs, except for albiglutide, significantly reduced weight [60]. Given this data, we do encourage clinicians to highly consider this medication class when treating patients with type 2 diabetes and obesity.

Table 1 provides an overview of common FDA-approved anti-obesity medications as well as medications often used off-label for weight management.

\section{Bariatric Surgery}

Patients with $\mathrm{BMI} \geq 40 \mathrm{~kg} / \mathrm{m}^{2}$ or with $\mathrm{BMI} \geq 35 \mathrm{~kg} \mathrm{~m}^{2}$ and 1 or more obesity-related comorbidities (e.g., diabetes, hyperlipidemia, or hypertension) qualify for bariatric surgery.
Qualifications for bariatric surgery will vary by health insurance. Bariatric surgery is a proven intervention that can safely lead to substantial weight loss. Expected weight loss is 20 $30 \%$ for laparoscopic sleeve gastrectomy (LSG) and 25-35\% for Roux-en-Y gastric bypass (RYGB) [61]. Referral for bariatric surgery should be considered for patients who fit these criteria and are motivated to lose weight [24].

LSG and RYGB are currently the most common bariatric surgeries performed currently. Bariatric surgery should especially be considered in patients with uncontrolled type 2 diabetes, as multiple studies have shown greater weight loss, decreased number of glucose-lowering medications including insulin, and higher quality of life in surgical patients compared to intensive diabetes medical therapy at 3 and 5 years after surgery $[62,63]$. More recent studies suggest that RYGB may have better potential at inducing diabetes remission than LSG [64].

\section{Endoscopic Procedures}

Bariatric endoscopic procedures are emerging as another treatment option for patients with obesity [65-67]. These therapies include a variety of devices and procedures, (e.g., intragastric balloons and sleeve gastroplasty) are minimally invasive, and can serve as a safer option for poor surgical candidates $[65$, 66]. Currently, however, endoscopic procedures have minimal coverage by insurance which currently limits their use in the US.

\section{A Word on Weight Maintenance}

PCPs should be ready to support patients who have intentionally lost weight to help them maintain their weight loss. For many patients, this can be a challenging phase; in fact, most people who lose weight through lifestyle interventions regain weight [68]. Data suggest that sustained lifestyle support and continued self-monitoring of diet, PA, and weight are helpful in promoting weight loss maintenance [69]. A recent international systematic review indicated that increased PA was the most consistent positive correlate of weight loss maintenance [70]. Increased exercise is required because there is a decrease in basal metabolism with weight loss, so increasing exercise allows for a higher calorie intake per day, which may be more sustainable. Additionally, eating more restaurant meals has been associated with weight regain [71], so encouraging patients to prepare most of their meals at home may help.

\section{Barriers and Challenges to Integrating Weight Management Treatments and Improving Obesity Care Within the PC Setting}

While the number of board-certified physicians in obesity medicine continues to increase, there are not enough obesity 


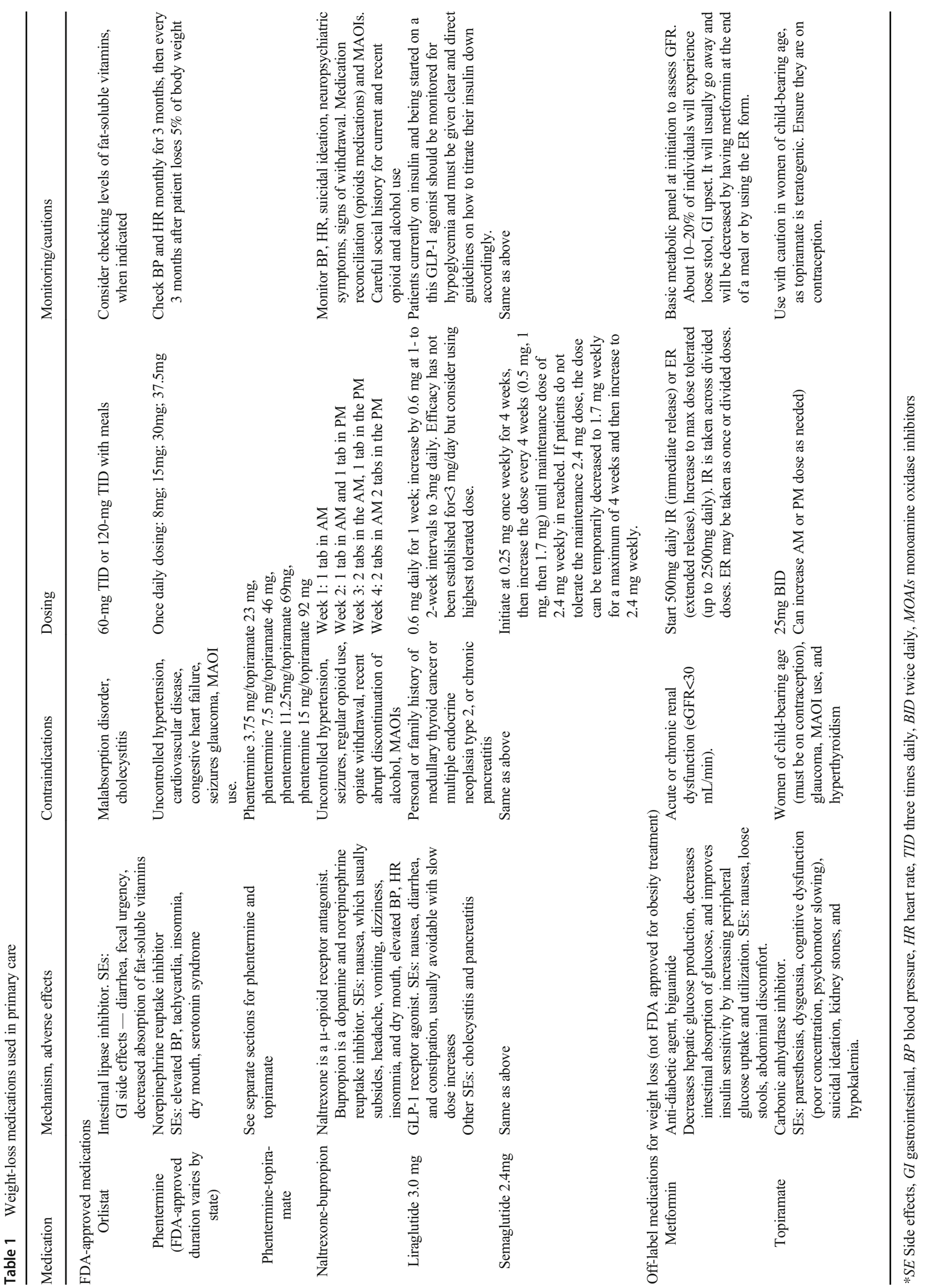


specialists to treat all patients requiring treatment. As of February 2019, 2577 physicians were certified by the American Board of Obesity Medicine (ABOM) [72]. With the increasing number of persons with obesity, there are approximately 11,000 new persons with obesity per every new ABOM diplomat [73]. Thus, PCPs must be able to provide succinct and practical weight loss advice to their patients.

On the provider level, lack of training and perceived lack of time are among the most commonly reported barriers to addressing weight management in PC $[74,75]$. One study showed that while $94 \%$ of internal medicine residents agreed it was their role to discuss nutrition with patients, only $14 \%$ felt adequately trained to provide nutrition counseling [76]. For PCPs who already have a disproportionate amount of work outside of the-face to-face encounter, it is difficult to find more time to conduct chart reviews, monitor patients, and communicate with patients about their progress with medications. When integrating weight management into clinical practice, it is important to allot time for the physician to review lifestyle modifications, behavioral changes, and monitoring measures (if indicated), to prescribe medications safely and effectively for obesity.

Apart from these logistical barriers, providers' beliefs about obesity and obesity stigma can also impact quality of care and medical decision-making [77]. Most Americans (59\%) still believe that obesity is caused by lack of willpower [78]. We know that this is not the case - the cause of obesity is multi-factorial and largely to do to factors (e.g., genetics, environment) that are beyond a person's individual control. For instance, the heritability index of obesity is $40-70 \%$ [79], which is similar to height, and there are $>120$ loci for polygenic forms of obesity [80]. A national web-based survey of health care providers showed that $59 \%$ of healthcare providers wait for the patient to bring up their weight before discussing treatment [75]. However, many patients report feeling stigmatized not only in their daily life, but also in healthcare settings and consequently avoid seeking healthcare [81-84]. Creating a welcoming and comfortable environment, taking on the responsibility to discuss patients' weight, and using neutral terms may help decrease stigma in the healthcare setting.

On the practice level, lack of reimbursement and infrastructure make obesity care challenging [85]. The Strategies to Overcome and Prevent (STOP) Obesity Alliance recommends that all personnel staffs are provided education and training on avoiding bias and stigma and that all resources are cataloged [86•*]. This requires a collective staff effort, time, and investment, and cannot be done alone by one provider. While some clinics may have the infrastructure and support to implement these measures, many do not. Furthermore, there may be few services available, such as dietitians, intensive behavioral programs, or even gyms. Another significant problem is the poor reimbursement by health insurance for obesity counseling and for anti-obesity medications [75, 87]. A national web-based survey of healthcare professionals showed that $53 \%$ of providers indicated that improved reimbursement would improve their ability to counsel patients about obesity [75].

\section{Integrating Clinical Guidelines into PC}

\section{Counseling Frameworks for Obesity}

Shared Decision-Making The shared decision-making (SDM) approach helps the provider and patient arrive at a mutually agreed upon treatment plan and can increase acceptance of medical or surgical treatment for obesity [88]. Patients' weight loss expectations largely overestimate what is achievable with any weight loss treatment [89]. Current studies show that only $\sim 10 \%$ of people with obesity lose $20 \%$ of their weight with intensive lifestyle and behavioral therapy [90], compared to over $70 \%$ of patients that lose greater than $20 \%$ of their weight with bariatric surgery, and $32 \%$ of patients with semaglutide $2.4 \mathrm{mg}$ weekly $[91,90]$. This dichotomy in expectation and biologic reality may lead to a feeling of failure even though the intervention was unlikely to give the anticipated results. PCPs can utilize an SDM model for obesity treatment counseling to discuss risks, benefits, and treatment expectations to enable patients to choose a treatment approach that will help them reach their health goals [92].

The 5As Model One counseling framework for having conversations about obesity is the 5As approach (assess, advise, agree, assist, and arrange) which has been studied for behavioral change in PC $[19,93]$. The STOP Obesity Alliance guide recommends using this approach with a 6th "A" (ask) added for weight management counseling in PC [86]. RuedaClausen et al. showed that applying the 5As to weight management increases the initiation of treatment of obesity. On that same note, Jay et al. showed that when physicians utilized more components of the 5As framework and were patientcentered in their approach, patients reported higher motivation to lose weight and intentions to change behavior [94] and patients of physicians trained in the 5 As lost more weight at 12 months [93]. Since addressing all the "As" (described in more detail below) may not be feasible in one visit unless it is a dedicated weight management visit, these can be discussed over multiple visits [95•].

\section{Suggested Approach to Discussing Treatment Options} Incorporating the 5As Model and SDM Ask permission to address weight - "can we talk about your weight today?" Using language such as "I am concerned about how your weight may be affecting your health. Today there are many effective treatments for obesity". Following with a question such as "would you be interested in having a visit to discuss 
effective treatments for obesity?" is a way to make the diagnosis and open discussion on treatment options.

Assess the patient's desired weight loss goal and reasons for wanting to lose weight. The clinician should also assess prior weight loss attempts and current diet and physical activity behaviors.

Advise about treatment options that match the patient's goals and are most likely to produce the desired results. Consider using the obesity treatment pyramid (Fig. 1) as a tool to guide this discussion. This is where the risks and benefits of treatment options should be discussed with the patient using the SDM approach.

Agree on weight loss, lifestyle, and behavioral goals with the patient. If health goals are not achieved, consider escalating the intervention or adjusting treatment goals.

Assist the patient by creating a plan. Documenting an obesity treatment plan can inform the care team of the patient goals and current treatment plan to improve individual patient success.

Arrange for patient engagement in the treatment plan and close follow-up.

Formulating an Obesity Treatment Plan When formulating a treatment plan, we recommend using a multi-modal approach that matches treatment efficacy with disease burden. Much like cancer is treated with a combination of modalities, treating obesity in a similar fashion can enhance long-term outcomes. Matching treatment to severity of disease is also important to avoid harmful failure experiences, which may limit future attempts at weight loss and likelihood of success. An obesity treatment plan might include lifestyle interventions, medications, self-monitoring, referrals (e.g., bariatric surgery), goals for next visit, and a follow-up plan. Figure 1 summarizes the expected weight loss for each treatment

Fig. 1 Obesity treatment pyramid developed by Angela Fitch, MD modality and may be a useful tool when speaking to patients. We provide further recommendations for PCPs in Table 2 based on clinical guidelines and expected health benefits from current treatments. Most importantly, an obesity treatment plan must be individualized to the patient's disease severity and health risks, health goals, and personal preferences.

Expanding Access to Obesity Care in the PC setting In addition to providing one-on-one counseling, there are several ways to change systems of care to improve obesity care in PC settings.

Telehealth visits: The Covid-19 pandemic has brought sweeping change to how medical care is provided, and the option of remote clinic visits will likely remain. With the ability to remotely monitor patients' weights and blood pressure, remote clinic visits may be an ideal option for obesity management, as an in-depth physical exam is usually not necessary for every obesity medicine visit [101]. Most visits will center around reviewing behavior changes, weight loss barriers and progress, and monitoring for pharmacotherapy side effects. Remote visits may even help patients avoid feelings of stigma produced by the structural environment of clinics (e.g., chairs and exam tables not being able to accommodate their size); the act of being weighed in public; and social stigma from medical staff and providers [102-105].

Team-based care: Team- and systems-based approaches can be utilized for lifestyle-focused treatment. Many research studies done in the PC settings have demonstrated the effectiveness of using various healthcare team members to deliver weight management services including nurses, lay educators, registered dietitians, behavioral

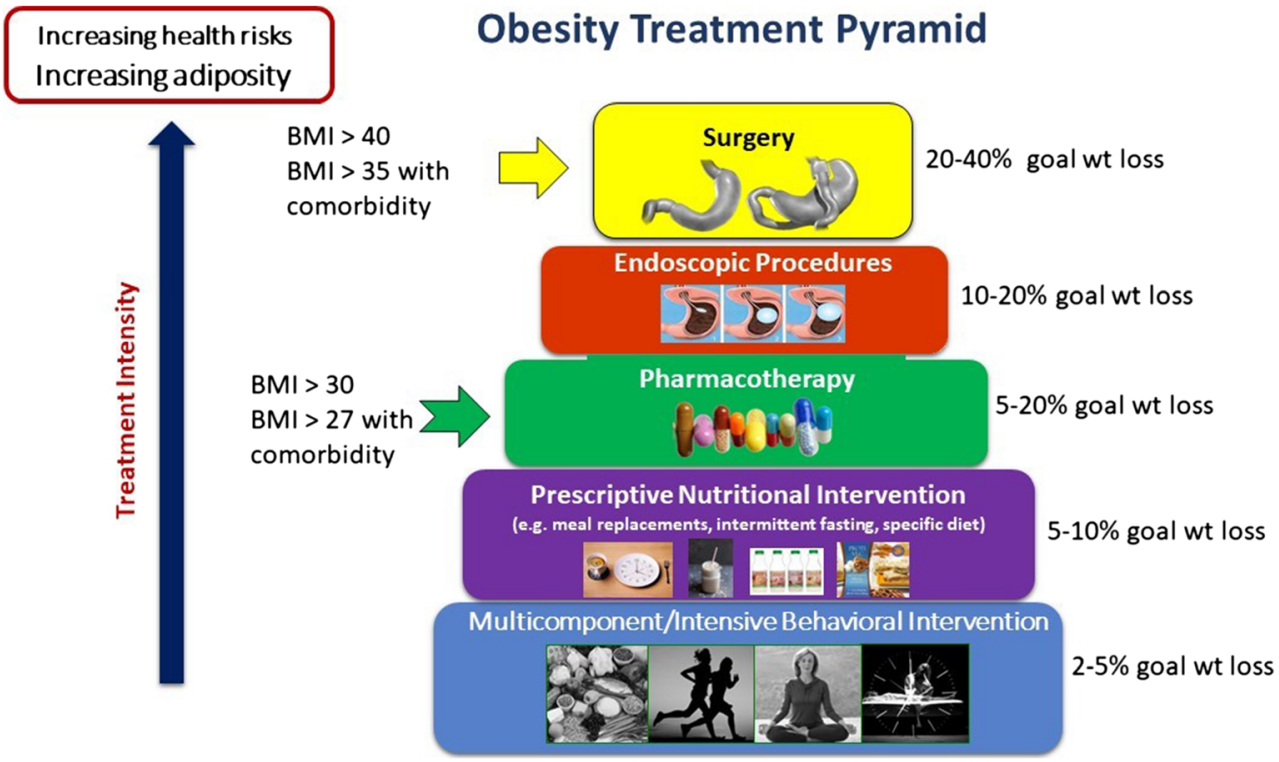


Table 2 Recommendations to potentially improve patient treatment success

- Diagnose obesity as class I, II, or III to identify appropriate treatment intensity.

- Aim for a 5-10\% weight loss for class I and/or if the goal is to prevent diabetes and/or promote remission of a mild-moderate complication (e.g., hypertension, dyslipidemia) [17]. Consider adding pharmacotherapy early on to increase the chance of a 5\% weight loss.

- Aim for a 10-20\% weight loss for patients with class II or III and/or a moderate complication (e.g., nonalcoholic fatty liver disease [96, 97], obstructive sleep apnea (OSA) [98, 99], or mild-moderate type 2 diabetes [100]).

Consider discussing surgery if lifestyle and pharmacotherapy are insufficient.

- Aim for a $>20 \%$ weight loss for class II or III and/or a severe complication (e.g., poorly controlled diabetes) and consider bariatric surgery early on as it is the most efficacious in reaching this desired weight loss goal, especially in the setting of diabetes (65).

- Create and document an obesity treatment plan.

- Develop a system for routine follow-up at a minimum of every 3 months (more frequent if possible) during the "core" weight loss phase, increasing interval follow-up during the "maintenance" phase (every 6-12 months).

therapists, and health coaches to reinforce lifestyle modifications [106-111]. A systematic review of PC-based interventions for obesity showed that several interventions delivered both in-person and remotely by interdisciplinary team members were more effective than usual care [112•]. Few trials of weight maintenance interventions have been conducted in primary care settings, but both telephone- and EHR-based supportive coaching have been shown to help prevent weight regain after intentional weight loss $[113,114]$. When available, PCPs can also consider utilizing "e-consults" for brief discussions with a weight management specialist.

Still, a challenge remains to sustainably staff and fund a PC-based weight management program. One potential mechanism for funding is to use chronic care management (CCM) codes, which can be used for patients with obesity and at least one other comorbid medical condition to appropriately increase the complexity of each visit and facilitate more frequent visits.

\section{Community Partnering}

Providing adequate obesity care in PC settings can be overwhelming, with limited time to provide in-depth behavioral counseling, so we encourage clinics to consider partnering with local community resources. The STOP Obesity Alliance recommends leveraging community providers and programs and online commercial programs [86••]. There is evidence to support the use of commercial programs like WW (formerly Weight Watchers) as a way to augment clinical care with a high-intensity weight loss program via increased self-monitoring and group support [115]. Clinics can also build relationships with local programs like YMCAs or free/lower cost programs (e.g., NYC Shape Up or Take Off Pounds Sensibly [TOPS] $[116,117])$ to connect patients with local options for supporting behavior change between clinic visits. Additionally, multiple studies have shown that faith- based organizations can deliver effective weight loss and health behavior interventions, especially in predominantly African-American communities [118, 119]. Consider compiling a list of such resources to provide to patients who are interested, as these may be their only opportunity to engage in safe exercise or other healthy behaviors $[86,120]$.

\section{Conclusion}

Obesity is the most common chronic disease that PCPs encounter. In this article, we reviewed the current treatments for obesity including lifestyle and behavioral interventions, anti-obesity medications, bariatric surgery, and endoscopic procedures. Clinically, utilizing strategies such as a SDM approach and the 5As to discuss treatment options can facilitate formulating an obesity treatment plan. Utilizing telehealth, a team-based approach, and community partnering can increase patient access to intensive behavioral interventions. We hope this article helps PCPs feel more comfortable discussing obesity and current treatment options with their patients and if needed, begin looking into ways to implement or improve obesity care in their practice. Future studies should evaluate other costeffective and efficient ways to implement obesity care into the PC setting.

\section{References}

Papers of particular interest, published recently, have been highlighted as:

- Of importance

•• Of major importance

1. World Health Organization. Obesity and overweight. . https:// wwwwhoint/news-room/fact-sheets/detail/obesity-andoverweight. 
2. D'Souza MJ, Bautista RC, Wentzien DE. Data talks: obesityrelated influences on US mortality rates. Res Health Sci. 2018;3(3):65-78.

3. Kyle TK, Dhurandhar EJ, Allison DB. Regarding obesity as a disease: evolving policies and their implications. Endocrinol Metab Clin North Am. 2016;45(3):511-20. https://doi.org/10. 1016/j.ecl.2016.04.004.

4. Müller MJ, Geisler C. Defining obesity as a disease. Eur J Clin Nutr. 2017;71(11):1256-8. https://doi.org/10.1038/ejcn.2017. 155.

5. Schwartz MW, Seeley RJ, Zeltser LM, Drewnowski A, Ravussin E, Redman LM, et al. Obesity pathogenesis: an endocrine society scientific statement. Endocr Rev. 2017;38(4):267-96. https://doi. org/10.1210/er.2017-00111.

6. Djalalinia S, Qorbani M, Peykari N, Kelishadi R. Health impacts of obesity. Pak J Med Sci. 2015;31(1):239-42. https://doi.org/10. 12669/pjms.311.7033.

7. Biener A, Cawley J, Meyerhoefer C. The impact of obesity on medical care costs and labor market outcomes in the US. Clin Chem. 2018;64(1):108-17. https://doi.org/10.1373/clinchem. 2017.272450.

8. Fitzpatrick SL, Stevens VJ. Adult obesity management in primary care, 2008-2013. Prev Med. 2017;99:128-33. https://doi.org/10. 1016/j.ypmed.2017.02.020.

9. Valero-Elizondo J, Aneni EC, Osondu CU, Grandhi GR, Virani SS, Nasir K. Gaps in provider lifestyle counseling and its adherence among obese adults with prediabetes and diabetes in the United States. Prev Med. 2019;129:105815. https://doi.org/10. 1016/j.ypmed.2019.105815.

10. de Heer H, Kinslow B, Lane T, Tuckman R, Warren M. Only 1 in 10 patients told to lose weight seek help from a health professional: a nationally representative sample. Am J Health Promot. 2019;33(7):1049-52. https://doi.org/10.1177/ 0890117119839904.

11. Ciciurkaite G, Moloney ME, Brown RL. The incomplete medicalization of obesity: physician office visits, diagnoses, and treatments, 1996-2014. Public Health Rep. 2019;134(2):141-9. https:// doi.org/10.1177/0033354918813102.

12. Greaney ML, Cohen SA, Xu F, Ward-Ritacco CL, Riebe D. Healthcare provider counselling for weight management behaviours among adults with overweight or obesity: a cross-sectional analysis of National Health and Nutrition Examination Survey, 2011-2018. BMJ Open. 2020;10(11):e039295. https://doi.org/ 10.1136/bmjopen-2020-039295.

13. Rui P OT. National ambulatory medical care survey: 2016 national summary tables. https://wwwcdegov/nchs/data/ahcd/ namcs_summary/2016_namcs_web_tablespdf. 2016.

14. Flegal KM, Kit BK, Orpana $\bar{H}$, Graubard BI. Association of allcause mortality with overweight and obesity using standard body mass index categories: a systematic review and meta-analysis. Jama. 2013;309(1):71-82. https://doi.org/10.1001/jama.2012. 113905.

15. Berrington de Gonzalez A, Hartge P, Cerhan JR, Flint AJ, Hannan $\mathrm{L}$, MacInnis RJ, et al. Body-mass index and mortality among 1.46 million white adults. N Engl J Med. 2010;363(23):2211-9. https:// doi.org/10.1056/NEJMoa1000367.

16. Whitlock G, Lewington S, Sherliker P, Clarke R, Emberson J, Halsey J, et al. Body-mass index and cause-specific mortality in 900000 adults: collaborative analyses of 57 prospective studies. Lancet. 2009;373(9669):1083-96. https://doi.org/10.1016/s01406736(09)60318-4.

17. Garvey WT, Mechanick JI, Brett EM, Garber AJ, Hurley DL, Jastreboff AM, et al. American Association of Clinical Endocrinologists and American College of Endocrinology comprehensive clinical practice guidelines for medical care of patients with obesity. Endocr Pract. 2016;22(Suppl 3):1-203. https://doi. org/10.4158/ep161365.Gl.

18. Curry SJ, Krist AH, Owens DK, Barry MJ, Caughey AB, Davidson KW, et al. Behavioral weight loss interventions to prevent obesity-related morbidity and mortality in adults: US preventive services task force recommendation statement. Jama. 2018;320(11):1163-71. https://doi.org/10.1001/jama.2018. 13022 .

19. Wharton S, Lau DCW, Vallis M, Sharma AM, Biertho L, Campbell-Scherer D, et al. Obesity in adults: a clinical practice guideline. Cmaj. 2020;192(31):E875-e91. https://doi.org/10. 1503/cmaj.191707.

20. The Diabetes Prevention Program (DPP): description of lifestyle intervention. Diabetes Care. 2002;25(12):2165-71. https://doi.org/ 10.2337/diacare.25.12.2165

21. Chan SH, Raffa SD. Examining the dose-response relationship in the veterans health administration ' s MOVE!(®) weight management program: a nationwide observational study. J Gen Intern Med. 2017;32(Suppl 1):18-23. https://doi.org/10.1007/s11606017-3992-3.

22. Maciejewski ML, Shepherd-Banigan M, Raffa SD, Weidenbacher HJ. Systematic review of behavioral weight management program MOVE! for veterans. Am J Prev Med. 2018;54(5):704-14. https:// doi.org/10.1016/j.amepre.2018.01.029.

23. Ahern AL, Wheeler GM, Aveyard P, Boyland EJ, Halford JCG, Mander AP, et al. Extended and standard duration weight-loss programme referrals for adults in primary care (WRAP): a randomised controlled trial. Lancet. 2017;389(10085):2214-25. https://doi.org/10.1016/s0140-6736(17)30647-5.

24. Jensen MD, Ryan DH, Apovian CM, Ard JD, Comuzzie AG, Donato KA, et al. 2013 AHA/ACC/TOS guideline for the management of overweight and obesity in adults: a report of the American College of Cardiology/American Heart Association Task Force on Practice Guidelines and The Obesity Society. Circulation. 2014;129(25 Suppl 2):S102-38. https://doi.org/10. 1161/01.cir.0000437739.71477.ee.

25. Meng Y, Bai H, Wang S, Li Z, Wang Q, Chen L. Efficacy of low carbohydrate diet for type 2 diabetes mellitus management: a systematic review and meta-analysis of randomized controlled trials. Diabetes Res Clin Pract. 2017;131:124-31. https://doi.org/10. 1016/j.diabres.2017.07.006.

26. Foreyt JP, Salas-Salvado J, Caballero B, Bulló M, Gifford KD, Bautista I, et al. Weight-reducing diets: are there any differences? Nutr Rev. 2009;67(Suppl 1):S99-101. https://doi.org/10.1111/j. 1753-4887.2009.00169.x.

27. Tsai AG, Bessesen DH. Obesity. Ann Intern Med. 2019;170(5): Itc33-itc48. https://doi.org/10.7326/aitc201903050 This comprehensive review of the causes, prevention, diagnosis, and management of obesity is an excellent clinical review of obesity and was used as a reference for some of the lifestyle recommendations outlined in this review.

28. Heymsfield SB, van Mierlo CA, van der Knaap HC, Heo M, Frier HI. Weight management using a meal replacement strategy: meta and pooling analysis from six studies. Int $\mathrm{J}$ Obes Relat Metab Disord. 2003;27(5):537-49. https://doi.org/10.1038/sj.ijo. 0802258.

29. Kruschitz R, Wallner-Liebmann S, Lothaller H, Luger M, Ludvik B. Long-term weight-loss maintenance by a meal replacement based weight management program in primary care. Obes Facts. 2017;10(2):76-84. https://doi.org/10.1159/000454836.

30. Astbury NM, Piernas C, Hartmann-Boyce J, Lapworth S, Aveyard $\mathrm{P}$, Jebb SA. A systematic review and meta-analysis of the effectiveness of meal replacements for weight loss. Obes Rev. 2019;20(4):569-87. https://doi.org/10.1111/obr.12816.

31. Swee W, Lee CL, Chee WSS. Translation of evidence to clinical practice for use of meal replacements in weight loss and obesity- 
lessons learned from research studies. J Nutr Food Sci. 2016;6: 541. https://doi.org/10.4172/2155-9600.1000541.

32. Shaw K, Gennat H, O ' Rourke P, Del Mar C. Exercise for overweight or obesity. Cochrane Database Syst Rev. 2006;4: Cd003817. https://doi.org/10.1002/14651858.CD003817.pub3.

33. Thorogood A, Mottillo S, Shimony A, Filion KB, Joseph L, Genest J, et al. Isolated aerobic exercise and weight loss: a systematic review and meta-analysis of randomized controlled trials. Am J Med. 2011;124(8):747-55. https://doi.org/10.1016/j. amjmed.2011.02.037.

34. Ismail I, Keating SE, Baker MK, Johnson NA. A systematic review and meta-analysis of the effect of aerobic vs. resistance exercise training on visceral fat. Obes Rev. 2012;13(1):68-91. https://doi.org/10.1111/j.1467-789X.2011.00931.x.

35. Moholdt T, Wisløff U, Lydersen S, Nauman J. Current physical activity guidelines for health are insufficient to mitigate long-term weight gain: more data in the fitness versus fatness debate (The HUNT study, Norway). Br J Sports Med. 2014;48(20):1489-96. https://doi.org/10.1136/bjsports-2014-093416.

36. Vanderwood KK, Hall TO, Harwell TS, Arave D, Butcher MK, Helgerson SD. Factors associated with the maintenance or achievement of the weight loss goal at follow-up among participants completing an adapted Diabetes Prevention Program. Diabetes Res Clin Pract. 2011;91(2):141-7. https://doi.org/10. 1016/j.diabres.2010.12.001.

37. Wadden TA, Neiberg RH, Wing RR, Clark JM, Delahanty LM, Hill JO, et al. Four-year weight losses in the Look AHEAD study: factors associated with long-term success. Obesity (Silver Spring). 2011;19(10):1987-98. https://doi.org/10.1038/oby.2011.230 In our article, we aim to bring attention to the long-term care that is required to prevent weight regain and the recurrence of obesity. The data from this four4-year Look AHEAD study provided key factors for preventing weight regain and achieving long-term success.

38. Catenacci VA, Ogden LG, Stuht J, Phelan S, Wing RR, Hill JO, et al. Physical activity patterns in the National Weight Control Registry. Obesity (Silver Spring). 2008;16(1):153-61. https:// doi.org/10.1038/oby.2007.6.

39. Vissers D, Hens W, Taeymans J, Baeyens JP, Poortmans J, Van Gaal L. The effect of exercise on visceral adipose tissue in overweight adults: a systematic review and meta-analysis. PLoS One. 2013;8(2):e56415. https://doi.org/10.1371/journal.pone.0056415.

40. Day DS, Gozansky WS, Van Pelt RE, Schwartz RS, Kohrt WM. Sex hormone suppression reduces resting energy expenditure and \{beta\}-adrenergic support of resting energy expenditure. J Clin Endocrinol Metab. 2005;90(6):3312-7. https://doi.org/10.1210/ jc.2004-1344.

41. LeBlanc ES, Patnode CD, Webber EM, Redmond N, Rushkin M, O'Connor EA. Behavioral and pharmacotherapy weight loss interventions to prevent obesity-related morbidity and mortality in adults: updated evidence report and systematic review for the US preventive services task force. Jama. 2018;320(11):1172-91. https://doi.org/10.1001/jama.2018.7777.

42. Bramante CT, Raatz S, Bomberg EM, Oberle MM, Ryder JR. Cardiovascular risks and benefits of medications used for weight loss. Front Endocrinol (Lausanne). 2019;10:883. https://doi.org/ 10.3389/fendo.2019.00883.

43. Kristensen SL, Rørth R, Jhund PS, Docherty KF, Sattar N, Preiss $\mathrm{D}$, et al. Cardiovascular, mortality, and kidney outcomes with GLP-1 receptor agonists in patients with type 2 diabetes: a systematic review and meta-analysis of cardiovascular outcome trials. Lancet Diabetes Endocrinol. 2019;7(10):776-85. https://doi.org/ 10.1016/s2213-8587(19)30249-9.

44. Saunders KH, Umashanker D, Igel LI, Kumar RB, Aronne LJ. Obesity pharmacotherapy. Med Clin North Am. 2018;102(1): 135-48. https://doi.org/10.1016/j.mcna.2017.08.010.
45. Apovian CM, Aronne LJ, Bessesen DH, McDonnell ME, Murad MH, Pagotto U, et al. Pharmacological management of obesity: an endocrine society clinical practice guideline. J Clin Endocrinol Metab. 2015;100(2):342-62. https://doi.org/10.1210/jc.20143415 This review still serves as one of the definitive guidelines on the pharmacological management of obesity and was referenced in this article for guidance of length of treatment.

46. Seifarth C, Schehler B, Schneider HJ. Effectiveness of metformin on weight loss in non-diabetic individuals with obesity. Exp Clin Endocrinol Diabetes. 2013;121(1):27-31. https://doi.org/10.1055/ s-0032-1327734.

47. Worsley R, Jane F, Robinson PJ, Bell RJ, Davis SR. Metformin for overweight women at midlife: a double-blind, randomized, controlled trial. Climacteric. 2015;18(2):270-7. https://doi.org/ 10.3109/13697137.2014.954997.

48. Rosenstock J, Hollander P, Gadde KM, Sun X, Strauss R, Leung A. A randomized, double-blind, placebo-controlled, multicenter study to assess the efficacy and safety of topiramate controlled release in the treatment of obese type 2 diabetic patients. Diabetes Care. 2007;30(6):1480-6. https://doi.org/10.2337/dc062001

49. Eliasson B, Gudbjörnsdottir S, Cederholm J, Liang Y, Vercruysse F, Smith U. Weight loss and metabolic effects of topiramate in overweight and obese type 2 diabetic patients: randomized double-blind placebo-controlled trial. Int J Obes (Lond). 2007;31(7):1140-7. https://doi.org/10.1038/sj.ijo.0803548.

50. Wilding J, Van Gaal L, Rissanen A, Vercruysse F, Fitchet M. A randomized double-blind placebo-controlled study of the longterm efficacy and safety of topiramate in the treatment of obese subjects. Int J Obes Relat Metab Disord. 2004;28(11):1399-410. https://doi.org/10.1038/sj.ijo.0802783.

51. Brownley KA, Berkman ND, Peat CM, Lohr KN, Cullen KE, Bann CM, et al. Binge-eating disorder in adults: a systematic review and meta-analysis. Ann Intern Med. 2016;165(6):409 20. https://doi.org/10.7326/m15-2455.

52. Guerdjikova AI, Mori N, Casuto LS, McElroy SL. Binge eating disorder. Psychiatr Clin North Am. 2017;40(2):255-66. https:// doi.org/10.1016/j.psc.2017.01.003.

53. McElroy SL, Arnold LM, Shapira NA, Keck PE Jr, Rosenthal NR, Karim MR, et al. Topiramate in the treatment of binge eating disorder associated with obesity: a randomized, placebocontrolled trial. Am J Psychiatry. 2003;160(2):255-61. https:// doi.org/10.1176/appi.ajp.160.2.255.

54. McElroy SL, Hudson JI, Capece JA, Beyers K, Fisher AC, Rosenthal NR. Topiramate for the treatment of binge eating disorder associated with obesity: a placebo-controlled study. Biol Psychiatry. 2007;61(9):1039-48. https://doi.org/10.1016/j. biopsych.2006.08.008.

55. Tata AL, Kockler DR. Topiramate for binge-eating disorder associated with obesity. Ann Pharmacother. 2006;40(11):1993-7. https://doi.org/10.1345/aph.1H178.

56. Hilbert A, Petroff D, Herpertz S, Pietrowsky R, Tuschen-Caffier B, Vocks S, et al. Meta-analysis of the efficacy of psychological and medical treatments for binge-eating disorder. J Consult Clin Psychol. 2019;87(1):91-105. https://doi.org/10.1037/ ccp0000358.

57. Correll CU, Maayan L, Kane J, Hert MD, Cohen D. Efficacy for psychopathology and body weight and safety of topiramateantipsychotic cotreatment in patients with schizophrenia spectrum disorders: results from a meta-analysis of randomized controlled trials. J Clin Psychiatry. 2016;77(6):e746-56. https://doi.org/10. 4088/JCP.15r10373.

58. Zheng W, Xiang YT, Xiang YQ, Li XB, Ungvari GS, Chiu HF, et al. Efficacy and safety of adjunctive topiramate for schizophrenia: a meta-analysis of randomized controlled trials. Acta 
Psychiatr Scand. 2016;134(5):385-98. https://doi.org/10.1111/ acps. 12631.

59. 9. Pharmacologic approaches to glycemic treatment: standards of medical care in diabetes-2021. Diabetes Care. 2021;44(Supplement 1):S111. https://doi.org/10.2337/dc21-S009.

60. Htike ZZ, Zaccardi F, Papamargaritis D, Webb DR, Khunti K, Davies MJ. Efficacy and safety of glucagon-like peptide-1 receptor agonists in type 2 diabetes: a systematic review and mixedtreatment comparison analysis. Diabetes Obes Metab. 2017;19(4): 524-36. https://doi.org/10.1111/dom.12849.

61. Hanipah ZNA, A.; Schauer, P.R. . Surgical treatment of obesity. In: Wadden TAB, G.A., editor. Handbook of Obesity Treatment. 2 ed2018. p. 367-92.

62. Schauer PR, Bhatt DL, Kirwan JP, Wolski K, Aminian A, Brethauer SA, et al. Bariatric surgery versus intensive medical therapy for diabetes - 5-year outcomes. N Engl J Med. 2017;376(7):641-51. https://doi.org/10.1056/NEJMoa1600869.

63. Schauer PR, Bhatt DL, Kirwan JP, Wolski K, Brethauer SA, Navaneethan SD, et al. Bariatric surgery versus intensive medical therapy for diabetes-3-year outcomes. N Engl J Med. 2014;370(21):2002-13. https://doi.org/10.1056/ NEJMoa1401329.

64. Yoshino M, Kayser BD, Yoshino J, Stein RI, Reeds D, Eagon JC, et al. Effects of diet versus gastric bypass on metabolic function in diabetes. N Engl J Med. 2020;383(8):721-32. https://doi.org/10. 1056/NEJMoa2003697.

65. Glass J, Chaudhry A, Zeeshan MS, Ramzan Z. New era: endoscopic treatment options in obesity-a paradigm shift. World $\mathrm{J}$ Gastroenterol. 2019;25(32):4567-79. https://doi.org/10.3748/ wjg.v25.i32.4567.

66. Saunders KH, Igel LI, Saumoy M, Sharaiha RZ, Aronne LJ. Devices and endoscopic bariatric therapies for obesity. Curr Obes Rep. 2018;7(2):162-71. https://doi.org/10.1007/s13679018-0307-x.

67. Sullivan S, Edmundowicz SA, Thompson CC. Endoscopic bariatric and metabolic therapies: new and emerging technologies. Gastroenterology. 2017;152(7):1791-801. https://doi.org/10. 1053/j.gastro.2017.01.044.

68. Barte JC, ter Bogt NC, Bogers RP, Teixeira PJ, Blissmer B, Mori TA, et al. Maintenance of weight loss after lifestyle interventions for overweight and obesity, a systematic review. Obes Rev. 2010;11(12):899-906. https://doi.org/10.1111/j.1467-789X. 2010.00740.x.

69. Befort CA, Stewart EE, Smith BK, Gibson CA, Sullivan DK, Donnelly JE. Weight maintenance, behaviors and barriers among previous participants of a university-based weight control program. Int J Obes (Lond). 2008;32(3):519-26. https://doi.org/10. 1038/sj.ijo.0803769.

70. Paixão C, Dias CM, Jorge R, Carraça EV, Yannakoulia M, de Zwaan M, et al. Successful weight loss maintenance: a systematic review of weight control registries. Obes Rev. 2020;21(5):e13003. https://doi.org/10.1111/obr.13003.

71. Gibbs BB, Tudorascu D, Bryce CL, Comer D, Fischer GS, Hess $\mathrm{R}$, et al. Lifestyle habits associated with weight regain after intentional loss in primary care patients participating in a randomized trial. J Gen Intern Med. 2020;35(11):3227-33. https://doi.org/10. 1007/s11606-020-06056-X.

72. Gudzune KA, Johnson VR, Bramante CT, Stanford FC. Geographic availability of physicians certified by the american board of obesity medicine relative to obesity prevalence. Obesity (Silver Spring). 2019;27(12):1958-66. https://doi.org/ 10.1002/oby.22628.

73. Hales CM, Carroll MD, Fryar CD, Ogden CL. Prevalence of obesity and severe obesity among adults: United States. NCHS Data Brief. 2017-2018;2020(360):1-8.
74. Kolasa KM, Rickett K. Barriers to providing nutrition counseling cited by physicians: a survey of primary care practitioners. Nutr Clin Pract. 2010;25(5):502-9. https://doi.org/10.1177/ 0884533610380057.

75. Petrin C, Kahan S, Turner M, Gallagher C, Dietz WH. Current attitudes and practices of obesity counselling by health care providers. Obes Res Clin Pract. 2017;11(3):352-9. https://doi.org/10. 1016/j.orcp.2016.08.005.

76. Vetter ML, Herring SJ, Sood M, Shah NR, Kalet AL. What do resident physicians know about nutrition? An evaluation of attitudes, self-perceived proficiency and knowledge. J Am Coll Nutr. 2008;27(2):287-98. https://doi.org/10.1080/07315724.2008. 10719702.

77. Kaplan LM, Golden A, Jinnett K, Kolotkin RL, Kyle TK, Look $\mathrm{M}$, et al. Perceptions of barriers to effective obesity care: results from the national ACTION study. Obesity (Silver Spring). 2018;26(1):61-9. https://doi.org/10.1002/oby.22054.

78. Paul Taylor CF, Peyton Craighill. Americans see weight problems everywhere but in the mirror pew research center. 2006; A social trends report.

79. Herrera BM, Lindgren CM. The genetics of obesity. Curr Diab Rep. 2010;10(6):498-505. https://doi.org/10.1007/s11892-0100153-z.

80. Singh RK, Kumar P, Mahalingam K. Molecular genetics of human obesity: a comprehensive review. C R Biol. 2017;340(2):87108. https://doi.org/10.1016/j.crvi.2016.11.007.

81. Tomiyama AJ, Carr D, Granberg EM, Major B, Robinson E, Sutin $\mathrm{AR}$, et al. How and why weight stigma drives the obesity 'epidemic' and harms health. BMC Med. 2018;16(1):123. https://doi. org/10.1186/s12916-018-1116-5.

82. Puhl R, Peterson JL, Luedicke J. Motivating or stigmatizing? Public perceptions of weight-related language used by health providers. Int J Obes (Lond). 2013;37(4):612-9. https://doi.org/10. 1038/ijo.2012.110.

83. Puhl RM, Peterson JL, Luedicke J. Parental perceptions of weight terminology that providers use with youth. Pediatrics. 2011;128(4):e786-93. https://doi.org/10.1542/peds.2010-3841.

84. Amy NK, Aalborg A, Lyons P, Keranen L. Barriers to routine gynecological cancer screening for White and African-American obese women. Int J Obes (Lond). 2006;30(1):147-55. https://doi. org/10.1038/sj.ijo.0803105.

85. Wadden TA, Butryn ML, Hong PS, Tsai AG. Behavioral treatment of obesity in patients encountered in primary care settings: a systematic review. Jama. 2014;312(17):1779-91. https://doi.org/ 10.1001/jama.2014.14173.

$86 . \bullet$ Weight can't wait. guide for management of obesity in the primary care setting. STOP strategies to overcome and prevent. 2020; Obesity Alliance(Milken Institute School of Public Health, The George Washington University). The STOP Obesity Alliance is a group of organizations committed to research, policy change, and provider education aimed at improving obesity management and reversing the obesity epidemic. Our review heavily referenced their innovative ways of creating change in the care and lives of people living with obesity.

87. Tsai AG, Asch DA, Wadden TA. Insurance coverage for obesity treatment. J Am Diet Assoc. 2006;106(10):1651-5. https://doi. org/10.1016/j.jada.2006.07.012.

88. Imbus JR, Funk LM. Shared decision-making in obesity treatment. In: Morton JM, Brethauer SA, DeMaria EJ, Kahan S, Hutter MM, editors. Quality in obesity treatment. Cham: Springer International Publishing; 2019. p. 155-65.

89. Foster GD, Wadden TA, Vogt RA, Brewer G. What is a reasonable weight loss? Patients' expectations and evaluations of obesity treatment outcomes. J Consult Clin Psychol. 1997;65(1):79-85. https://doi.org/10.1037//0022-006x.65.1.79. 
90. Maciejewski ML, Arterburn DE, Van Scoyoc L, Smith VA, Yancy WS Jr, Weidenbacher HJ, et al. Bariatric surgery and long-term durability of weight loss. JAMA Surg. 2016;151(11): 1046-55. https://doi.org/10.1001/jamasurg.2016.2317.

91. Wilding JPH, Batterham RL, Calanna S, Davies M, Van Gaal LF, Lingvay I, et al. Once-weekly semaglutide in adults with overweight or obesity. N Engl J Med. 2021. https://doi.org/10.1056/ NEJMoa2032183.

92. Lee YC, Wu WL. Shared decision making and choice for bariatric surgery. Int J Environ Res Public Health. 2019;16(24). https://doi. org/10.3390/ijerph16244966.

93. Jay MR, Gillespie CC, Schlair SL, Savarimuthu SM, Sherman SE, Zabar SR, et al. The impact of primary care resident physician training on patient weight loss at 12 months. Obesity (Silver Spring). 2013;21(1):45-50. https://doi.org/10.1002/oby.20237.

94. Jay M, Gillespie C, Schlair S, Sherman S, Kalet A. Physicians' use of the 5As in counseling obese patients: is the quality of counseling associated with patients ' motivation and intention to lose weight? BMC Health Serv Res. 2010;10:159. https://doi.org/10. 1186/1472-6963-10-159.

95. Schlair S, Moore S, McMacken M, Jay M. How to deliver highquality obesity counseling in primary care using the $5 \mathrm{As}$ framework. Journal of Clinical Outcomes Management. 2012;19:221-9 Starting the conversation about weight can be the most difficult part of obesity management. This paper provides guidance for obesity counseling in the primary care setting using the 5As framework.

96. Wong VW, Chan RS, Wong GL, Cheung BH, Chu WC, Yeung DK, et al. Community-based lifestyle modification programme for non-alcoholic fatty liver disease: a randomized controlled trial. J Hepatol. 2013;59(3):536-42. https://doi.org/10.1016/j.jhep.2013. 04.013.

97. Vilar-Gomez E, Martinez-Perez Y, Calzadilla-Bertot L, TorresGonzalez A, Gra-Oramas B, Gonzalez-Fabian L, et al. Weight loss through lifestyle modification significantly reduces features of nonalcoholic steatohepatitis. Gastroenterology. 2015;149(2): 367-78.e5; quiz e14-5. https://doi.org/10.1053/j.gastro.2015.04. 005 .

98. Foster GD, Borradaile KE, Sanders MH, Millman R, Zammit G, Newman AB, et al. A randomized study on the effect of weight loss on obstructive sleep apnea among obese patients with type 2 diabetes: the Sleep AHEAD study. Arch Intern Med. 2009;169(17):1619-26. https://doi.org/10.1001/archinternmed. 2009.266

99. Kuna ST, Reboussin DM, Borradaile KE, Sanders MH, Millman RP, Zammit G, et al. Long-term effect of weight loss on obstructive sleep apnea severity in obese patients with type 2 diabetes. Sleep. 2013;36(5):641-9a. https://doi.org/10.5665/sleep.2618.

100. Lean ME, Leslie WS, Barnes AC, Brosnahan N, Thom G, McCombie L, et al. Primary care-led weight management for remission of type 2 diabetes (DiRECT): an open-label, clusterrandomised trial. Lancet. 2018;391(10120):541-51. https://doi. org/10.1016/s0140-6736(17)33102-1.

101. Lakshminarayan K, Westberg S, Northuis C, Fuller CC, Ikramuddin F, Ezzeddine M, et al. A mHealth-based care model for improving hypertension control in stroke survivors: pilot RCT. Contemp Clin Trials. 2018;70:24-34. https://doi.org/10. 1016/j.cct.2018.05.005.

102. Gudzune KA, Beach MC, Roter DL, Cooper LA. Physicians build less rapport with obese patients. Obesity (Silver Spring). 2013;21(10):2146-52. https://doi.org/10.1002/oby.20384.

103. Gudzune KA, Bennett WL, Cooper LA, Bleich SN. Patients who feel judged about their weight have lower trust in their primary care providers. Patient Educ Couns. 2014;97(1):128-31. https:// doi.org/10.1016/j.pec.2014.06.019.
104. Gudzune KA, Bleich SN, Richards TM, Weiner JP, Hodges K, Clark JM. Doctor shopping by overweight and obese patients is associated with increased healthcare utilization. Obesity (Silver Spring). 2013;21(7):1328-34. https://doi.org/10.1002/oby.20189.

105. Phelan SM, Dovidio JF, Puhl RM, Burgess DJ, Nelson DB, Yeazel MW, et al. Implicit and explicit weight bias in a national sample of 4,732 medical students: the medical student CHANGES study. Obesity (Silver Spring). 2014;22(4):1201-8. https://doi.org/10.1002/oby.20687.

106. Kumanyika SK, Morales KH, Allison KC, Russell Localio A, Sarwer DB, Phipps E, et al. Two-year results of think health! ¡Vive Saludable!: a primary care weight-management trial. Obesity (Silver Spring). 2018;26(9):1412-21. https://doi.org/10. 1002/oby.22258.

107. Appel LJ, Clark JM, Yeh HC, Wang NY, Coughlin JW, Daumit $\mathrm{G}$, et al. Comparative effectiveness of weight-loss interventions in clinical practice. N Engl J Med. 2011;365(21):1959-68. https:// doi.org/10.1056/NEJMoa1108660.

108. Wadden TA, Volger S, Sarwer DB, Vetter ML, Tsai AG, Berkowitz RI, et al. A two-year randomized trial of obesity treatment in primary care practice. N Engl J Med. 2011;365(21):196979. https://doi.org/10.1056/NEJMoa1109220.

109. Ma J, Yank V, Xiao L, Lavori PW, Wilson SR, Rosas LG, et al. Translating the Diabetes Prevention Program lifestyle intervention for weight loss into primary care: a randomized trial. JAMA Intern Med. 2013;173(2):113-21. https://doi.org/10.1001/2013. jamainternmed.987.

110. Bennett GG, Steinberg D, Askew S, Levine E, Foley P, Batch BC, et al. Effectiveness of an app and provider counseling for obesity treatment in primary care. Am J Prev Med. 2018;55(6):777-86. https://doi.org/10.1016/j.amepre.2018.07.005.

111. Weinstock RS, Trief PM, Cibula D, Morin PC, Delahanty LM. Weight loss success in metabolic syndrome by telephone interventions: results from the SHINE Study. J Gen Intern Med. 2013;28(12):1620-8. https://doi.org/10.1007/s11606-0132529-7.

112. Tronieri JS, Wadden TA, Chao AM, Tsai AG. Primary care interventions for obesity: review of the evidence. Curr Obes Rep. 2019;8(2):128-36. https://doi.org/10.1007/s13679-019-00341-5 This review discussed evidence-based interventions obesity treatment in the primary care setting. Our article referenced this article when discussing specific tools that can be utilized to integrate obesity care into the primary care setting.

113. Voils CI, Olsen MK, Gierisch JM, McVay MA, Grubber JM, Gaillard L, et al. Maintenance of weight loss after initiation of nutrition training: a randomized trial. Ann Intern Med. 2017;166(7):463-71. https://doi.org/10.7326/m16-2160.

114. Conroy MB, McTigue KM, Bryce CL, Tudorascu D, Gibbs BB, Arnold J, et al. Effect of electronic health record-based coaching on weight maintenance: a randomized trial. Ann Intern Med. 2019;171(11):777-84. https://doi.org/10.7326/m18-3337.

115. Bramante CT, Lee CJ, Gudzune KA. Treatment of obesity in patients with diabetes. Diabetes Spectr. 2017;30(4):237-43. https://doi.org/10.2337/ds17-0030.

116. Shape Up NYC 2021 [cited 2021 March 2021]. Available from: https://www.nycgovparks.org/programs/recreation/shape-up-nyc.

117. Tops Club Inc. 2021 [cited 2021 March 2021]. Available from: https://www.tops.org/tops/TOPS/Default.aspx.

118. Maynard MJ. Faith-based institutions as venues for obesity prevention. Curr Obes Rep. 2017;6(2):148-54. https://doi.org/10. 1007/s13679-017-0257-8.

119. Lancaster KJ, Carter-Edwards L, Grilo S, Shen C, Schoenthaler AM. Obesity interventions in African American faith-based organizations: a systematic review. Obes Rev. 2014;15(Suppl 4):159 76. https://doi.org/10.1111/obr.12207. 
120. Dietz WH, Solomon LS, Pronk N, Ziegenhorn SK, Standish M, Longjohn MM, et al. An integrated framework for the prevention and treatment of obesity and its related chronic diseases. Health Aff (Millwood). 2015;34(9):1456-63. https://doi.org/10.1377/ hlthaff.2015.0371.
Publisher's Note Springer Nature remains neutral with regard to jurisdictional claims in published maps and institutional affiliations. 